\title{
The Kyoto Protocol: In force?
}

$\mathrm{F}$ eb. 16, 2005, marks the entry into force of the Kyoto Protocol and its country-specific targets to reduce emissions of the "greenhouse gases" responsible for global warming. Most scientists agree that the earth's surface air temperature is rising, that this trend has accelerated dramatically since about 1970 (Fig. 1), and that human activity is now its major driver.

By 2100 the global average surface air temperature will be $1.4^{\circ} \mathrm{C}$ to $5.8^{\circ} \mathrm{C}$ warmer than in the period $1961-1990$, even taking into account full implementation of plans to reduce fossil fuel use. In Canada, especially at this time of year, the prospect of our climate warming by a few tenths of a degree per decade hardly seems alarming. But, in the Arctic, such incremental change is sufficient to irreparably disrupt ecosystems and ice reservoirs, with profound implications for traditional lifestyles. The regional effects of climate change will be uneven and unpredictable, but it is clear that the most fragile ecosytems and vulnerable populations will also be the most at risk.

In this issue ${ }^{1}$ (see page 501) Sari Kovats and Andrew Haines update an earlier review ${ }^{2}$ with a discussion of the emerging health effects of climate change, such as the 2003 heat wave in France, which resulted in more than 14000 deaths. But, despite what science and common sense tells us, Canada's Kyoto promises have faltered. As our economy has expanded (achieving 40\% growth in GDP between 1990 and 2002), so have emissions, which are now roughly $25 \%$ higher than in 1990. Canada has committed to achieve, by 2012, a 6\% reduction relative to 1990 levels. It seems evident that we will not meet this target. As we write, the government is floating the idea of easing the Kyoto obligations of "large emitters" (the 700 companies that produce $50 \%$ of Canada's emissions), even as it launches a chipper "One Tonne Challenge" aimed at persuading individuals to clean up their act (www.climatechange.gc.ca /onetonne/english/index.asp?pid=179).

This latter goal might be achievable. Canada ranks in the top 10 countries in per-capita annual consumption of fossil fuels (16.93 metric tons of $\mathrm{CO}_{2}$ per person). The European Union does considerably better (eg., 9.52 in Denmark and 6.16 in France). ${ }^{3}$ Over $80 \%$ of Canada's greenhouse gas emissions in 2002 were in the energy sector (transportation, heating and manufacturing). ${ }^{4}$ Green technologies offer some hope, but buy-in from government and consumers has been glacially slow. Solar panels are not sprouting on rooftops. There are more SUVs than hybrids to choose from in car dealer showrooms. Municipalities are still choosing 4-lane commuter roads over light rail.

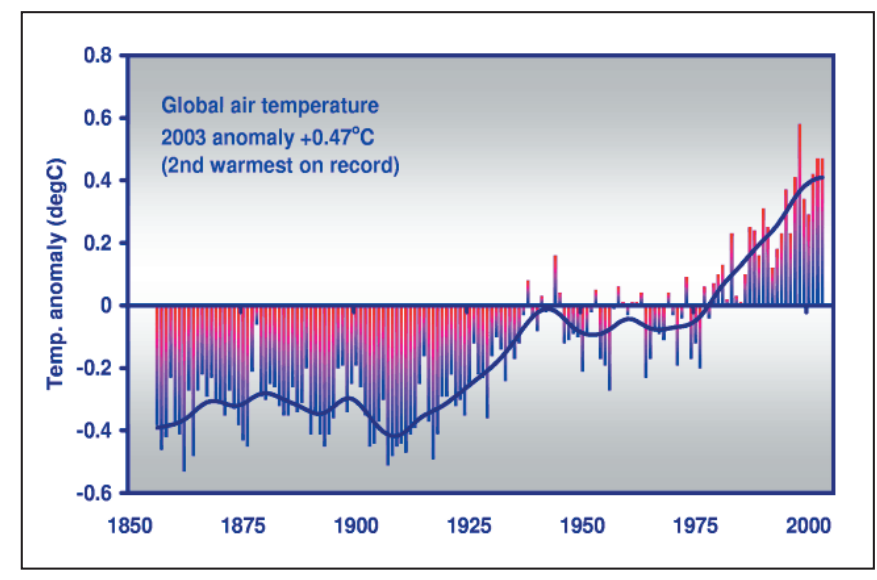

Fig. 1: Global temperature record. Reproduced, with permission, from The Whitney Laboratory for Marine Bioscience, University of Florida.

At least Kyoto has forced participating countries to construct inventories of their energy consumption. ${ }^{4}$ Health care delivery, which now represents about $10 \%$ of the Canadian economy, will have to address its contribution to global warming and environmental degradation in general. The huge ecological footprint of hospitals has already been quantified, ${ }^{5}$ and some institutions are finding ways to minimize their environmental impact. Physicians, many of whom vigorously supported signing on to the Protocol, should take their own "green inventory" and consider what material and behavioural aspects of their practice are due for a retrofit — such as replacing face-to-face visits in clinics and hospitals with real-time audio (and video) communication. At the very least we ought to be assessing the effects of avoidable travel on our patients and the environment. And not to be forgotten are the daily opportunities for physicians to remind patients and the public about the intimate connection between the state of the environment and the state of our health. - CMA7

\section{References}

1. Kovats RS, Haines A. Global climate change and health: recent findings and future steps. CMA7 2005;172(4):501-2.

2. Haines A, McMichael AJ, Epstein PR. Environment and health: 2. Global climate change and health. CMA7 2000;163(6):729-34.

3. International Energy Agency. Key world energy statistics 2004. Available: http://library.iea.org/dbtw-wpd/Textbase/nppdf/free/2004/keyworld2004.pdf (accessed 2005 Jan 21).

4. Environment Canada. Canada's Greenhouse Gas Inventory, 1990-2002. Available: www.ec.gc.ca/pdb/ghg/1990_02_report/p3_e.cfm (accessed 2005 Jan 21).

5. Jameton A, Pierce J. Environment and health: 8 . Sustainable health care and emerging ethical responsibilities [review]. CMA7 2001;164(3):365-9. 